\section{Gastric ulcer: is endoscopy always necessary?}

Crucial to the management of gastric ulceration is the accurate distinction between benign and malignant lesions. Controversy continues over how this should be achieved, the conclusion from a recent retrospective study ${ }^{1}$ being that all gastric ulcers should be assessed endoscopically and tissue obtained for histological diagnosis by means of multiple biopsy and brush cytology.

Good-quality double-contrast radiology of the stomach appears to permit accurate prediction of whether a gastric ulcer is benign or malignant provided that the "guideline" pattern around the ulcer crater is adequately shown. ${ }^{2}$ If this is so endoscopy could be reserved for doubtful cases rather than being a routine procedure.

\section{Patients, methods, and results}

We accepted for the study 80 patients in whom a gastric ulcer had been shown radiologically and the criteria for a benign lesion were satisfied. Patients with pyloric and prepyloric lesions and those who had undergone gastric surgery were excluded.

All barium-meal examinations were performed by consultant radiologists using a double-contrast method. In the radiological differentiation of a benign from a malignant lesion no importance was attached to the site, size, or shape of the ulcer, attention being directed to the guidelines surrounding the crater. The criteria for a benign ulcer were that the guidelines, which converge on an ulcer often from a considerable distance, had to run straight and reduce in thickness until they joined the margin of the ulcer crater. ${ }^{3}$ This is in contrast to the mucosal pattern around a malignant lesion, when the guidelines are bent, do not reduce in thickness as they approach the lesion, and often stop short of the ulcer crater $^{3}$ (figure).

All the patients underwent endoscopy, carried out by a consultant physician, within four weeks of the barium-meal examination. A minimum of four biopsy specimens were taken from the edge of the ulcer (one from each quadrant when possible) and one or two specimens from the ulcer base. Further histological material was also available from those patients who ultimately underwent operation.

The age range of the 80 patients was $32-91$ (mean 61 ) years; 53 were men and 27 women. Histological examination of the gastric mucosal biopsy specimens showed no evidence of malignancy in any of the patients studied. Twenty-one patients $(26 \%)$ subsequently came to operation and histological examination of the resected specimens showed no evidence of carcinoma.
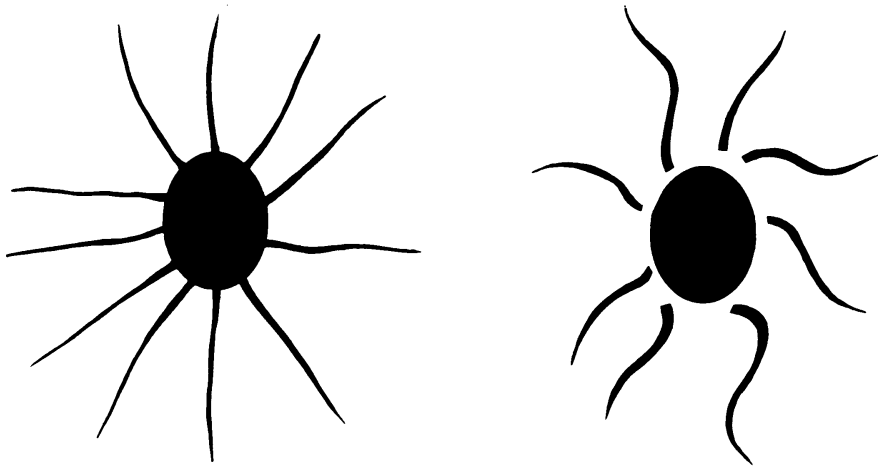

Guideline patterns indicating benign ulcer (left) and malignant lesion (right).

\section{Comment}

This prospective study was undertaken to establish whether analysis of the guideline pattern around a gastric ulcer as shown by doublecontrast barium-meal examination performed by experienced radiologists permitted an accurate prediction of whether the lesion was benign or malignant. Using this criterion confident radiological diagnosis of a benign ulcer was not disproved by either endoscopic biopsy or subsequent operation with histological examination of the resected specimen.

It might be argued that some of the lesions diagnosed as benign both radiologically and endoscopically may subsequently prove to be malignant, but this was not observed during the period of the study, the longest follow-up being four years.

Although mindful of the need to diagnose gastric cancer as early as possible, we nevertheless think that when a patient has been investigated with double-contrast barium-meal examination the more invasive and time-consuming technique of endoscopy may be reserved for patients in whom radiological assessment of whether a gastric ulcer is present is equivocal; the guideline pattern around the ulcer is not adequately shown; or the guideline pattern around the ulcer crater suggests malignancy.

The need for careful follow-up remains, however, with these two diagnostic techniques being complementary rather than mutually exclusive.

We thank Dr W G Scott-Harden for his continued interest and encouragement.

${ }^{1}$ Mountford RA, Brown P, Salmon PR, Alvarenga C, Neumann CS, Read AE. Gastric cancer detection in gastric ulcer disease. Gut 1980;21:9-17.

2 Ichikawa $\mathrm{H}$. Differential diagnosis between benign and malignant ulcers of the stomach. Clin Gastroenterol 1973;2:329-43.

${ }^{3}$ Scott-Harden WG. The stomach and duodenum. In: Lodge $T$, Steiner $\mathrm{RE}$, eds. Recent advances in radiology and medical imaging 6 . Edinburgh : Churchill Livingstone, 1979:65-77.

(Accepted 9 April 1981)

Cumberland Infirmary, Carlisle CA2 7HY

R H SALTER, MB, FRCP, consultant physician

D K GILL, MB, BS, senior house officer

T G GIRDWOOD, MB, FRCR, consultant radiologist

R H MCNEIL, MB, FRCR, consultant radiologist

G ATHEY, MB, FRCR, consultant radiologist

\section{Hyperoxaluria and recurrent stone formation apparently cured by short courses of pyridoxine}

Calcium oxalate urolithiasis is becoming increasingly common in Britain and other developed countries. Urinary oxalate is probably more important than urinary calcium in the cause, and any way of reducing urinary oxalate concentrations therefore seems to be important. We describe here two unusual cases of recurring calcium oxalate urolithiasis with hyperoxaluria which responded remarkably to pyridoxine.

\section{Patients and results}

Both patients were studied mainly as outpatients with normal activities and diet. Their short admissions to hospital did not seem to alter urinary composition. Urinary oxalate and glycollate concentrations were measured by enzymatic techniques. ${ }^{2}$

Case 1-This 42-year-old man had suffered painless haematuria in 1948 when an intravenous urogram showed slight left hydronephrosis. He suffered further haematuria in 1949 and 1952 and renal colic in 1959, 1963, and 1972 and subsequently every few months. Several stones were removed from the right ureter by Dormiar basket. One was analysed and showed calcium, phosphorus, and oxalate. Investigations at the General Hospital, Northampton, showed normal plasma and 24-hour urinary calcium concentrations. He continued to pass small stones and in March 1977 was referred to our hospital. The dietary history was unremarkable except for his consumption of one to two pints of milk a day and a low intake of oxalate-rich foods, except strawberries in season. There was no family history of urinary stones. Physical examination showed nothing abnormal; 24-hour urinary concentrations were normal except for oxalate $(0.78$ and $0.83 \mathrm{mmol}(70$ and $75 \mathrm{mg})$ ) and glycollate $(0.79 \mathrm{mmol}(60 \mathrm{mg})$ ) (upper limits of normal 0.45 and $0.36 \mathrm{mmol}$ respectively (41 and $27 \mathrm{mg}$ )). Pyridoxine $200 \mathrm{mg}$ twice a day was started in April 1977 but stopped in August after urinary oxalate and glycollate concentrations returned to normal. His further progress is shown in the figure. $\mathrm{He}$ passed a 10-mg stone in June 1977 and gravel in December 1977 but since then has had no recurrence of hyperoxaluria or symptoms of stone.

Case 2-This 26-year-old woman suffered haematuria in 1973 and stones were removed from her right kidney in April 1974. Hypercalciuria was treated with cellulose phosphate until September 1977, when this was changed to hydrochlorothiazide. Despite this treatment she had passed a further 10 to 12 stones by September 1978. She was admitted to our hospitals in November 1978, after several weeks off thiazide. She was $180 \mathrm{~cm}$ tall and weighed $68.4 \mathrm{~kg}$. There was no skeletal asymmetry. Her plasma concentrations were normal, as were 24-hour urinary excretions, except for calcium $(11.8$ and $16.9 \mathrm{mmol}(472$ and $676 \mathrm{mg}))$, oxalate $(0.61$ and $0.69 \mathrm{mmol}(55$ and $62 \mathrm{mg})$ ), and glycollate $(0.80$ and $0.84 \mathrm{mmol}(61$ and $64 \mathrm{mg}))$. The lowest $\mathrm{pH}$ levels after two ammonium chloride urine acidification tests were 5.71 and 5.33 . One of her brothers had normal urinary oxalate concentrations $(0.21 \mathrm{mmol} / 24 \mathrm{~h}(27 \mathrm{mg}))$. Pyridoxine was started in November 1978 and stopped in January 1980. She passed two stones in May 1979 (27\% calcium 